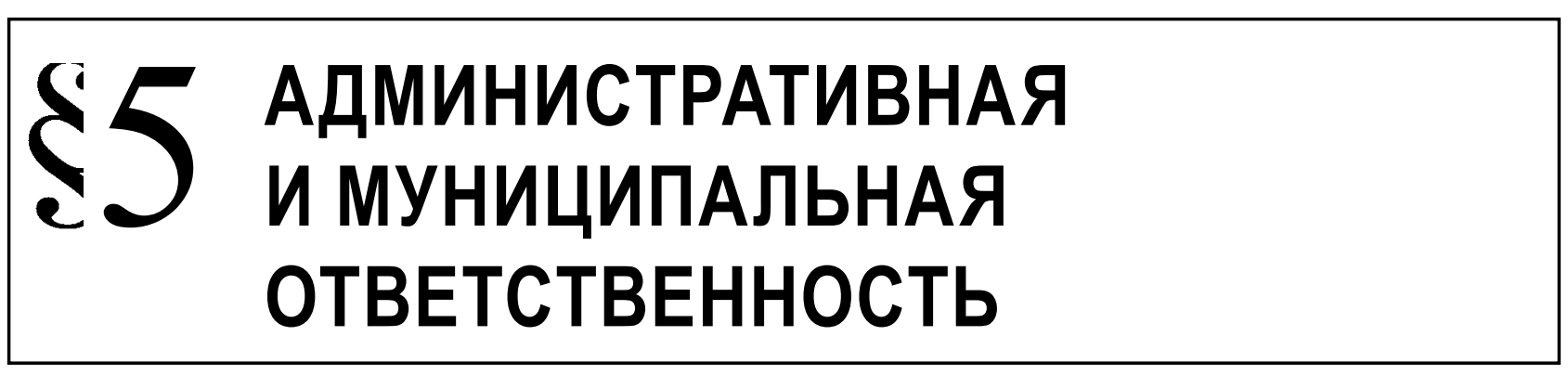

Адмиралова И.А.

\title{
АДМИНИСТРАТИВНО-ЮРИСДИКЦИОННАЯ ДЕЯТЕЛЬНОСТЬ ПОЛИЦИИ ПО ОБЕСПЕЧЕНИЮ ПРАВ И СВОБОД ГРАЖДАН
}

\begin{abstract}
Аннотация. Предметом статьи являются правовые и организационные проблемы деятельности полиции в срере реализации законодательства об административных правонарушениях. Объектом статьи являются общественные отношения, складывающиеся в связи с осуществлением полицией административной юрисдикции. Автор подробно рассматривает проблему обеспечения прав и свобод граждан в соответствующем направлении деятельности, обращает внимание на проблемы связанные с применением к гражданам мер административного принуждения. Особое внимание уделяется обеспечению прав и свобод граждан в производстве по делам об административных правонарушениях, которое осуществляется в органах полиции. Методологическую основу статьи составили современные достижения теории познания. В процессе исследования применялись общефилософский, теоретический методы (диалектика, системный метод, анализ, синтез, аналогия, дедукция, наблюдение), традиционно правовые методы, а также методы, используемые в конкретно-социологических исследованиях. В статье сформулированы предложения направленные на совершенствование организации и осуществления административно-юрисдикционной деятельности полиции, особенно в деле обеспечения прав и свобод граждан. Особым вкладом автора является то, что он доказывает необходимость приостановить фиксацию административных правонарушений в автоматическом режиме, хотя бы до тех пор, пока есть технические сбои. Новизна исследования также состоит в том, что автор предлагает распространить практику назначения наказаний ниже минимального предела, это будет отвечать принципу гуманизма.
\end{abstract}

Ключевые слова: юрисдикция, производство, стадия, протокол, жалоба, сотрудник, полиция, контроль, принуждение, ответственность.

Review. The subject of the article is a range of legal and organizational problems of police activity in the sphere of implementation of the legislation on administrative offences. The object of this article includes public relations arising during the exercise of administrative jurisdiction by the police. The author considers the problem of provision of rights and freedoms of citizens in the respective sphere of activity, draws attention to the problems of use of coercive measures against citizens. Special attention is paid to the provision of rights and freedoms of citizens in the police proceedings on administrative offences. The methodology of the research contains the recent achievements of epistemology. The author uses general philosophical, theoretical methods (dialectics, the systems method, analysis, synthesis, analogy, deduction, observation), traditional legal methods and the methods used in special sociological research.The author proposes the ways of improvement of organization and implementation of the administrative-jurisdictional policing, especially in the provision of rights and freedoms of citizens. The specific contribution of the author consists in proving of the necessity to suspend the registration of administrative offences automatically, at least while there are technical malfunctions. The novelty of the research consists in the fact that the author proposes to extend the practice of sentencing below the minimum limit, it will meet the principle of humanism.

Keywords: coercion, control, police, officer, complaint, protocol, stage, process, jurisdiction, responsibility.

$\mathrm{P}$ оссийская полиция реализует правоприменительную деятельность по самому широкому спектру вопросов, каждый из которых самым непосредственным образом касается обеспечения прав и свобод граждан. Одним из самых содержательных направлений в работе полиции является ее административно-юрисдикционная деятельность, в ходе которой обеспечивается решение 
целого комплекса задач, связанных с применением мер административного воздействия, а также охраной и защитой прав и свобод человека и гражданина. Однако административно-юрисдикционная деятельность не может существовать изолированно от других направлений административной работы полиции, более того, она логически с ними взаимосвязана, выполняя при этом в соответствующем механизме охранительную функцию. Как писал в свое время Е.В. Додин «...административно-юрисдикционная деятельность является составной частью административной деятельности органов внутренних дел и, соответственно, обладает всеми чертами последней. Вместе с тем, административно-юрисдикционная деятельность имеет специфические признаки, которые позволяют говорить о ней, как о самостоятельном виде административной деятельности» [1].

Отметим также, что административно-юрисдикционная деятельность закрепляет необходимую процессуальную форму, в которой реализуется компетенция полиции по применению мер обеспечения производства по делам об административных правонарушениях, административных наказаниях (ст. 3.2, ст. 27.1 КоАП России), а также иных мер административного воздействия или охраны. Исходя из своего содержания, административноюрисдикционная деятельность является деятельностью процессуального характера, поэтому в ходе ее реализации очень важно соблюдать установленную процессуальную форму, которая в значительной степени является гарантий соблюдения прав и свобод граждан. В этой связи представляется верным тезис O.C. Лебедченко о том, что «...административно-процессуальными нормами должна регламентироваться юрисдикционная деятельность государства, деятельность по применению иных мер государственного принуждения, а также деятельность по реализации регулятивных норм, носящих позитивный характер» [2].

В ходе правоприменительной деятельности полиции можно заметить, что посредством административного процесса реализуется целый ряд охранительных и регулятивных норм административного права, причем число последних становится все больше. Обусловлено это рядом объективных обстоятельств, преимущественно связанных с вовлечением полиции в целый ряд, по сути, гражданских (хозяйственных) отношений. Несмотря на это, все же не следует пренебрегать охранительной составляющей административного процесса, которая применяется полицией, в частности в сфере обеспечения прав и свобод граждан. Административный процесс, реализуемый сотрудниками полиции, пронизывает практически всю ее (полиции) деятельность, особенно в том его аспекте, который связан с обеспечением прав и свобод граждан.

Представляется необходимым отметить, что административный процесс - это феномен, который в настоящее время никем не оспаривается, однако относительно его содержания существуют различные точки зрения, которые по-разному определяют его роль и значение, в частности в сфере защиты прав и свобод граждан. Полиция, как субъект исполнительной власти реализует целый ряд, можно даже сказать, комплекс административных производств, которые конструктивно являются составными частями административного процесса. Среди административных производств, реализуемых полицией, особое место принадлежит административно-юрисдикционным производствам, которые, как уже ранее отмечалось, помогают сотрудникам полиции осуществлять свою работу по обеспечению правопорядка, а также защите прав и свобод граждан.

Однако нужно отметить специально, что соответствующие производства могут достигнуть обозначенной цели только в том случае, если в ходе их реализации будут должным образом обеспечены все материальные и процессуальные гарантии прав и свобод граждан. Причем такое обеспечение должно находиться в приоритете у каждого сотрудника полиции, который осуществляет обозначенное направление административной деятельности полиции. Необходимая база для этого закреплена в Федеральном законе от 7 февраля 2011 г. «0 полиции», в котором определяется основополагающий принцип, согласно которому полиция предназначена для защиты жизни, здоровья, прав и свобод граждан (ст. 1). Кроме того, одним из основных направлений деятельности полиции является защита личности, общества, государства от противоправных посягательств (ст. 2).

Говоря о содержании административноюрисдикционной деятельности полиции, нужно отметить, что в ее конструкцию укладывается производство по делам об административных правонарушениях, производство по применению различных мер административного принуждения, а также производство по жалобам граждан. Это, пожалуй, основные административные производства, которые качественно определяют сущность рассматриваемого направления деятельности российской полиции. В этой связи кратко 
раскроем особенности деятельности полиции по реализации обозначенных административных производств. Не вызывает сомнения тот факт, что одним из самых крупных и содержательных административных производств в деятельности полиции, является производство по делам об административных правонарушениях. Как верно отметил Н.Н. Цуканов «...органы внутренних дел относятся к числу тех субъектов, которые активно реализуют законодательство Российской Федерации об административных правонарушениях» [3].

Однако следует подчеркнуть, что законодательство об административных правонарушениях не может реализовываться в отрыве от иных нормативных правовых актов, причем различной отраслевой принадлежности. Обусловлено это особенностями данного законодательства, кроме того, немаловажным обстоятельством является то, что полиции обеспечивает защиту самых различных прав и свобод граждан, которые вытекают из трудовых, социальных, а также финансовых правоотношений и др.

В деле реализации законодательства об административных правонарушениях у органов внутренних дел, а в настоящее время уже и у полиции накоплен достаточно большой опыт работы в этом направлении. Однако нужно признать, что далеко не на всех этапах развития законодательства об административных правонарушениях в приоритете были именно вопросы обеспечения прав и свобод граждан. Подобное положение вещей добавляло в свое время весьма существенную репрессивность в деле реализации законодательства об административных правонарушениях вообще и административных наказаний в частности.

Административно-юрисдикционные меры, практически на протяжении всего периода своего развития, весьма серьезно ограничивали различного рода права и свободы граждан, так как они касались имущественных и неимущественных прав того лица, в отношении которого они непосредственно применялись. Несмотря на то, что средства административной юрисдикции активно развивались на протяжении многих лет, государство также активно стремилось к формированию необходимых гарантий защиты прав и свобод граждан в отношении которых осуществлялось соответствующее государственное воздействие. Такой подход был вызван формированием международно-правовых стандартов обеспечения прав и свобод человека, а также развитием внутренней административной политики, касающейся защиты прав и свобод граждан. Не вызывает сомнения тезис о том, что объективно необходимо учитывать публично-правовые интересы и разумно соотносить их с интересами соблюдения прав и свобод граждан в отношении которых применяются меры административного принуждения, в том числе и административно-процессуального характера. Как отмечала Н.Г. Салищева «...именно здесь необходимы четкие правила, которые определяют порядок применения мер административного принуждения, а также положения, которые могут обеспечивать необходимые гарантии правильного и обоснованного осуществления административной юрисдикции» [4].

Исходя из обозначенных доктринальных положений, собственно, и закрепляются базовые положения КоАП России. Так, в нем определяется, что задачами законодательства об административных правонарушениях являются: защита личности, охрана прав и свобод человека и гражданина, охрана здоровья граждан (ст. 1.2); лицо подлежит административной ответственности только за те административные правонарушения, в отношении которых установлена его вина (ст. 1.5). При применении мер административного принуждения не допускаются решения и действия (бездействие), унижающие человеческое достоинство (ст. 1.6), нужно также подчеркнуть, что лицо, совершившее административное правонарушение, подлежит ответственности на основании закона, действовавшего во время совершения соответствующего административного правонарушения (1.7);

административное наказание не может иметь своей целью унижение человеческого достоинства физического лица, совершившего административное правонарушение, или причинение ему физических страданий (ст. 3.1).

Кроме того, в деле обеспечения прав и свобод граждан, важным обстоятельством является, например, предписание о том, что вред, причиненный незаконным применением мер обеспечения производства по делу об административном правонарушении, подлежит возмещению в порядке, предусмотренном законодательством (ст. 27.1).

Обозначенные положения, по сути, являются принципами, основополагающими положениями, которые необходимо учитывать в деятельности полиции при реализации законодательства об административных правонарушениях, эти положения также нужно соблюдать и при осуществлении производства по делам об административных правонарушениях, а также при применении административных наказаний. 
Как вытекает из содержания нашего исследования, основополагающим нормативным правовым актом, который регламентирует деятельность полиции в рассматриваемой в сфере, является Кодекс Российской Федерации об административных правонарушениях (2001 г.). Отметим, что такой закон, как КоАП и, соответственно, такой вид юридической ответственности, как административная ответственность, существует только в нашей стране и некоторых государствах постсоветского пространства. В европейских странах рассматриваемого института административной ответственности не сформировано. Так, например в Германии сходные с предметом КоАП общественные отношения регламентируются законом «0 нарушении общественного порядка», предписания которого достаточно серьезны и даже репрессивны, в связи с чем обозначенный закон вполне обоснованно можно отнести скорее к предмету регулирования уголовного права, нежели права административного. Обратим внимание и на то, что закон «Об общественном порядке» существует и в Англии. В этой связи, возможно, было бы целесообразно поставить вопрос о разработке аналогичного закона и в нашей стране. Это укладывалось бы в общую концепцию охраны прав и свобод граждан в сфере общественного порядка.

Приведенный европейский опыт вполне обоснован, поскольку от состояния общественного порядка, атмосферы спокойствия и благоденствия в общественных местах зависит уровень безопасности отдельно взятого человека, и как следствие этого, создавались бы более эффективные условия для функционирования целого ряда социальных и экономических институтов.

В нашей стране Кодекс об административных правонарушениях и институт административной ответственности в целом, также выполняет весьма существенную полицейскую функцию, однако чрезмерно высокие административные штрафы и неразвитая система общественного благоустройства постепенно превратили полицейские меры в средства пополнения доходов бюджетов различного уровня. Подобная ситуация выглядит весьма пагубно, как для дела охраны общественного порядка и обеспечения общественной безопасности, так и для защиты прав и свобод граждан. Административная работа полиции в рассматриваемом нами аспекте, постепенно превращается в деятельность фискальную, объективным выражением которой стало количество составленных протоколов, наложенных административных штрафов, и, самое главное, количество денежных средств, которые уплачиваются по окончании соответствующего исполнительного производства.

Данную тенденцию поддержать нельзя, поскольку она уводит работу полиции в несколько иную плоскость, далекую от сферы правоохраны и защиты прав и свобод граждан. Административная деятельность полиции и такая ее форма, как юрисдикционная деятельность, должны быть, прежде всего, направлены в правоохранительное русло. Необходимо еще раз подчеркнуть, что основная цель обозначенной работы должна быть связана с предупреждением и пресечением различного рода правонарушений, обеспечением надлежащего уровня безопасности личности, а также формированием необходимых условий для развития общества и хозяйственной (экономической) деятельности. Фискальная и коммерческая составляющая в деятельности полиции должны быть полностью исключены, а основные усилия полиции сосредоточены, как уже отмечалось, на деле обеспечения прав и свобод граждан.

Возвращаясь к характеристике КоАП России, следует отметить, что он максимально и комплексно закрепляет институт административной ответственности, а если быть точнее, оптимально определяет систему материальных и процессуальных норм, которые регулируют порядок применения административных наказаний и мер обеспечения производства по делам об административных правонарушениях.

Однако, несмотря на это, потенциал данного кодекса в деле обеспечения прав и свобод граждан реализуется, к сожалению, не в полном объеме. Правоприменительная практика полиции, в ходе которой реализуется соответствующие разделы КоАП России, далеко не оптимальна, предстоит еще много сделать для того, чтобы максимально полно обеспечить соблюдение прав и свобод, как участников производства по делам об административных правонарушениях, так и других лиц, которые прямо или косвенно оказались под действием обозначенного закона.

Несмотря на предпринимаемые усилия, попрежнему сотрудниками полиции нарушаются самые различные права и свободы граждан. В частности, к наиболее типичным и существенным упущениям в рассматриваемой сфере относятся такие нарушения прав и свобод граждан, как привлечение их к административной ответственности при отсутствии признаков и состава административного правонарушения. Имеют место случаи нарушения установленных законом сроков давности привлечения к административной ответственно- 
сти, составления протоколов и вынесение постановлений об административном правонарушении без указания в них всех необходимых сведений, кроме того, очень редко разъясняются процессуальные права и обязанности участникам производства по делу об административном правонарушении и др.

Помимо этого, к числу весьма существенных нарушений прав граждан в юрисдикционой деятельности полиции можно также отнести неверную квалификацию ряда административных правонарушений, нарушения процессуального порядка административного задержания граждан, случаи необоснованного задержания без составления протоколов, а также превышения установленных законом сроков административного задержания. Имеют место случаи весьма формального исполнения сотрудниками полиции своих полномочий по доказыванию виновности привлекаемых к административной ответственности лиц, выяснения принципиально значимых для разрешения конкретного дела обстоятельств. Обращает на себя внимание и то, что сотрудники полиции очень редко прибегают к опросу свидетелей, потерпевших, медицинскому освидетельствованию в установленном порядке участников производства по делам об административных правонарушениях на предмет состояния их опьянения и т.п.

Контрольно-надзорные, а также проверочные мероприятия регулярно обнаруживают факты упрощенчества при производстве по делам об административных правонарушениях, в частности, например, оно может осуществляться без вызова и опроса лица, привлекаемого к административной ответственности, без разъяснений ему его процессуальных прав, исследования документов. Нередко вскрываются случаи игнорирования обстоятельств, исключающих производство по делу. Встречаются случаи ненадлежащего оформления процессуальных актов, нередки ситуации, связанные с сокрытием процессуальных документов, неознакомление с процессуальными документами участников производства по делам об административных правонарушениях. На некоторые подобные обстоятельства обращалось внимание и в научной литературе ранее.

В частности, А.С. Дугенец в свое время высказался относительно реализации одного из аспектов рассматриваемой проблемы. Так, он в частности отметил, что «...определенное значение в деле реализации конституционных прав граждан на защиту своих интересов призваны сыграть вопросы правового регулирования вручения копии постановления по делу об административном правонарушении. Однако не- обходимо еще много сделать для того, чтобы это процессуальное действие превратилось в эффективный механизм защиты прав и свобод граждан» [5].

Говоря о других проблемах обозначенного вопроса, необходимо сказать, что по-прежнему выявляются случаи нарушения подведомственности при рассмотрении отдельных категорий дел об административных правонарушениях, имеет место бездействие в вопросах исполнения примененных административных наказаний, в частности не реализуются в полном объеме предусмотренные законом меры по реальному взысканию наложенных административных штрафов. Далеко не оптимально применяются предусмотренные законом средства, которые необходимы для выявления причин административных правонарушений и способствующих им условий в целях их последующего устранения. Все эти, а также ряд иных обстоятельств снижают эффективность работы полиции в соответствующей сфере, а также влекут за собой нарушения различных прав и свобод граждан или, по крайней мере, создают для таких нарушений весьма благоприятную почву.

Перечисленные, а также ряд других факторов вызывают объективную необходимость совершенствования правовых и организационных основ административно-юрисдикционной деятельности полиции, кроме того, необходимо качественно изменить критерии оценки ее эффективности. Вполне назрела необходимость включения в КоАП России предписаний, которые давали бы гражданам дополнительные гарантии защиты их прав, свобод и законных интересов в производстве по делам об административных правонарушениях, а сотрудников полиции соответствующие предписания обязывали бы обеспечивать необходимые процессуальные права всем лицам, которые заинтересованы в конечном итоге соответствующего производства.

Компетенция органов внутренних дел (полиции) в вопросах реализации законодательства об административных правонарушениях самая разнообразная и содержательная. Данное обстоятельство обусловлено как историческими причинами, так и универсальностью работы рассматриваемой правоохранительной структуры. С точки зрения охраны общественного порядка и обеспечения общественной безопасности, посыл законодателя вполне обоснован (ст. 23.3 КоАП России). Однако, как показывает практика, организация и осуществление производства по делам об административных правонарушениях в органах внутренних дел (полиции) оставляет желать лучшего. Именно ор- 
ганизационная составляющая в деле осуществления административно-юрисдикционной деятельности полиции таит в себе ряд реальных рисков нарушения прав и свобод граждан.

В 2007 г. в КоАП России появилась статья, определяющая, что к административной ответственности за административные правонарушения в области дорожного движения, в случае фиксации этого правонарушения работающими в автоматическом режиме специальными техническими средствами, привлекаются собственники (владельцы) транспортных средств (ст. 2.6.1). Такая практика выявления правонарушений есть в целом ряде зарубежных государств, и она весьма существенно повлияла на повышение уровня правопорядка, а также защиту прав и свобод граждан от различного рода противоправных посягательств. Установление аналогичных предписаний в нашей стране с самого начала вызвало неоднозначную реакцию как в обществе, так и в профессиональной среде. Вполне обоснован тезис о нарушении в ряде случаев, например, презумпции невиновности, а также о некоторых иных процессуальных моментах негативного характера, связанных с оформлением выявленных в таком режиме административных правонарушений.

Выглядит не вполне убедительным предписание о том, что собственник транспортного средства освобождается от административной ответственности, если в ходе рассмотрения жалобы на постановление по делу об административном правонарушении будет подтвержден факт, что в момент фиксации административного правонарушения транспортное средство находилось во владении или в пользовании другого лица (ч. 2 ст. 2.6.1).

Граждане получая уведомление (постановление) о факте фиксации административного правонарушения в автоматическом режиме примерно представляет, как по такого рода жалобам осуществляется работа, догадывается о вероятных юридических последствиях ее рассмотрения, в связи с чем технически, попросту говоря, смирившись, уплачивает административный штраф - не обращая внимание на презумпцию невиновности, а также другие формальности производства по делам об административных правонарушениях. Такое положение вещей делает обычного человека, по сути беззащитным и беспомощным в соответствующих обстоятельствах.

Показатели статистики, относительно выявленных с помощью видео фиксации административных правонарушений растут, суммы уплаченных административных штрафов увеличиваются в геометрической прогрессии, а уровень безопасно- сти дорожного движения, а также защиты прав и законных интересов участников дорожного движения катастрофически снижается. О том, достигнута ли цель такого административно-правового регулирования - вопрос по большей части риторический.

Обращает на себя внимание и другое обстоятельство, затронуть которое также объективно необходимо, поскольку оно касается соблюдения прав граждан в рассматриваемой сфере административно-правового регулирования. Нередки случаи, когда гражданин исполнил в установленный законом срок примененное к нему административное наказание в виде административного штрафа - т.е. уплачено. Гражданин, согласен с тем, что совершил административное правонарушение, предусмотренное ст. 12.9 КоАП России и это правонарушение, зафиксированное камерой, имело место. Ситуация более чем распространенная, однако оплата административного штрафа вовсе не гарантирует того, что данный факт вовремя попадет в информационную базу Госавтоинспекции и за гражданином не будет числиться неисполненной соответствующая административная обязанность со всеми вытекающими для него (гражданина) негативными последствиями.

В настоящее время типичны ситуации, когда гражданина пытаются привлечь к административной ответственности все те же сотрудники Госавтоинспекции за уклонение от исполнения административного наказания (ст. 20.25 КоАП России) только потому, что соответствующий человек есть в информационной базе и за ним значится неисполненная обязанность по уплате административного штрафа, хотя фактически человек в полном объеме исполнил свои обязанности по оплате примененного к нему административного наказания в виде штрафа. Подобная ситуация весьма серьезно снижает авторитет полиции, ведет к нарушению прав граждан, подрывает доверие к закону и всей системе технического обеспечения безопасности дорожного движения.

Технические сбои отчасти объективны. В этой связи было бы вполне правильным фиксировать административные правонарушения в области безопасности дорожного движения в автоматическом режиме только на хорошо оборудованных и просторных автомагистралях. В крупных городах, где большая концентрация автотранспорта, зачастую имеют место плохо оборудованные дороги, дефицит парковочных мест и т.п. - следует рассмотреть возможность приостановления фиксации административных правонарушений в автоматическом режиме - хотя бы до того времени, когда технические сбои перестанут быть столь частыми. 
Связано это с тем, что подобное фиксирование административных правонарушений - это, в сущности, сбор административных штрафов в плановом и систематическом режиме, не имеющий ничего общего с обеспечением безопасности дорожного движения, предупреждением административных правонарушений, а также защитой прав и свобод граждан. Такой подход - не проявление либерализма, а объективная необходимость защиты имущественных прав граждан от фискального произвола, который сегодня, к сожалению, имеет место в сфере обеспечения безопасности дорожного движения.

В настоящее время можно наблюдать положительную тенденцию смягчения административно-наказательной политики, которая выражается в предоставлении возможности субъекта юрисдикции применять административное наказание в случаях, предусмотренных КоАП России, ниже низшего предела установленного санкцией соответствующей статьи (ст. 4.1). Данную тенденцию необходимо поддержать и расширить возможности применения административного наказания, в частности в виде административного штрафа ниже низшего предела. Такой подход будет в определенной степени соответствовать идее обеспечения прав и свобод граждан в производстве по делам об административных правонарушениях, а также гуманизации административной ответственности.

КоАП России закрепляет не только материальные и процессуальные средства и основания применения мер административного принуждения, он также определяет средства защиты, а именно - институт обжалования, или, как иногда говорят, «право жалобы». Отметим, что совокупность средств обжалования в производстве по делам об административных правонарушениях можно назвать институтом защиты прав и свобод граждан.

Не заостряя внимания на детали обозначенного института, обратим внимание еще на одно производство, которое реализуется в деятельности полиции - производство по жалобам граждан. Традиционно считается, что жалоба - это вид обращения, в котором содержится требование о восстановлении нарушенного права, или исключение каких-либо препятствий для реализации имеющегося у гражданина права. Нужно признать, что, к сожалению, совсем не все благополучно обстоит в организации обеспечения соответствующего конституционного права гражданина в самых различных органах государственной власти и управления, в том числе и в МВД России.
Необходимо отметить, что государственная власть в России во все времена понимала важность и необходимость правового регулирования права жалобы, в этой связи ее нельзя упрекнуть в том, что в регулировании этого вопроса был пробел. С самого начала развития новой российской государственности, прослеживается понимание значения института обжалования действий (бездействия) должностных лиц. Власть инициирует принятие Закона РФ от 27 апреля 1993 г. «Об обжаловании в суд действий и решений, нарушающих права и свободы граждан».

Согласно этого закона, каждый гражданин вправе обратиться с жалобой в суд, если считает, что неправомерными действиями (решениями) государственных органов или должностных лиц, государственных служащих нарушены его права и свободы. Исходя из этого, можно сделать вывод о том, что «право жалобы», реализуемое как в административном, так и в судебном порядке, носит абсолютный характер и не может быть ограничено законом.

Следует особо подчеркнуть, что обжалованы могут быть любые действия (бездействия) различных должностных лиц, в том числе и органов полиции, которыми нарушены права и свободы гражданина; созданы препятствия осуществлению гражданином его прав и свобод; незаконно на гражданина возложена какая-либо обязанность или он незаконно привлечен к какой-либо ответственности. Такие предписания в полной мере соответствуют требованиям международных стандартов в области обеспечения прав и свобод человека и гражданина. Они могут быть реализованы как в судебном, так и в административном порядке.

Работу с жалобами граждан в органах государственной власти и управления в настоящее время регламентирует Федеральный закон от 2 мая 2006 г. «0 порядке рассмотрения обращений граждан Российской Федерации», в развитие вышеназванного закона в системе МВД России принят приказ МВД России от 12 сентября 2013 г. № 707 «Об утверждении Инструкции об организации рассмотрения обращений граждан в системе Министерства внутренних дел Российской Федерации».

Согласно данного приказа, рассмотрение обращений в системе МВД России включает в себя следующие этапы: прием и первичную обработку обращений; регистрацию и учет обращений; принятие организационных решений о порядке рассмотрения обращений; рассмотрение обращений по существу и принятие по ним решений; подготовку и направление ответов на обращения; хранение обращений и материалов по их рассмотрению; 
личный прием граждан; анализ рассмотрения обращений; контроль за рассмотрением обращений.

Нужно признать, что в упомянутом приказе МВД России достаточно четко закреплены основные стадии (этапы) работы с обращениями граждан вообще и с жалобами в частности, однако, несмотря на это, нередки случаи формального отношения к обозначенному направлению работы. Граждане, в силу субъективных причин не получают удовлетворение своих требований, изложенных в жалобе. Все еще имеют место случаи, когда жалобу рассматривает то должностное лицо полиции, действие (бездействие) которого, собственно, и обжалуется. Подобное положение вещей снижает правоохранительный потенциал нормативной правовой базы, которая регламентирует производство по жалобам в органах полиции и не способствует защите прав и свобод граждан.
Для исправления подобной ситуации вполне возможно создавать общественные комиссии по работе с жалобами граждан. Эти комиссии могли бы работать с обращениями граждан, в которых обжалуются действия или бездействия должностных лиц полиции. Возможно, также привлекать к работе в таких комиссиях граждан-правозащитников, а также самые различные институты гражданского общества, которые заинтересованы в соответствующей работе. Такой подход исключит корпоративную солидарность в работе с жалобами, повысит качество работы с обращениями граждан. Все это, в конечном итоге будет способствовать защите прав и свобод граждан, которые реализуются в сфере внутренних дел, это также повысит ответственность должностных лиц полиции, кроме того, это может способствовать укреплению уровня законности и дисциплины в системе Министерства внутренних дел Российской Федерации.

\section{Библиография:}

1. Додин Е.В. Доказывание в административно-юрисдикционной деятельности органов внутренних дел. - Киев. 1985. - С. 8.

2. Лебедченко О.С. Административно-процессуальные формы реализации лицензионно-разрешительной деятельности: состояние и перспективы. - М., 1999. - С. 7.

3. Цуканов Н.Н. Теория и практика производства по делам об административных правонарушениях, осуществляемого органами внутренних дел: Автореф. дис. ... д-ра. юрид наук. - Челябинск, 2011. - С. 3.

4. Салищева Н.Г. Гражданин и административная юрисдикция. - М., 1979. - С. 72.

5. Дугенец А.С. Копия постановления по делу об административном правонарушении как средство защиты конституционных прав граждан // Конституционное и муниципальное право. - 2002. - № 1. - С. 17.

6. Куракин А.В. Административно-юрисдикционная деятельность полиции: проблемы теории // Административное и муниципальное право. - 2014. - 3. - C. 259 - 271. DOI: 10.7256/1999-2807.2014.3.11115.

7. Куракин А.В. Компетенция полиции в сфере реализации законодательства об административных правонарушениях // NB: Административное право и практика администрирования. - 2013. - 4. - С. 28 - 48. DOI: 10.7256/23069945.2013.4.8841. URL: http://www.e-notabene.ru/al/article_8841.html

8. Адмиралова И.А., Кареева-Попелковская К.А. Меры административного пресечения и механизм их реализации полицией в целях обеспечения прав и свобод граждан // Административное и муниципальное право. - 2014. - 4. C. 351 - 359. DOI: 10.7256/1999-2807.2014.4.11434.

9. Куракин А.В. Компетенция полиции в сфере реализации законодательства об административных правонарушениях // Административное и муниципальное право. - 2013. - 6. - С. 624 - 630. DOI: 10.7256/1999-2807.2013.06.5.

\section{References (transliterated):}

1. Dodin E.V. Dokazyvanie v administrativno-yurisdiktsionnoi deyatel'nosti organov vnutrennikh del. - Kiev. 1985. - S. 8

2. Lebedchenko O.S. Administrativno-protsessual'nye formy realizatsii litsenzionno-razreshitel'noi deyatel'nosti: sostoyanie i perspektivy. - M., 1999. - S. 7.

3. Tsukanov N.N. Teoriya i praktika proizvodstva po delam ob administrativnykh pravonarusheniyakh, osushchestvlyaemogo organami vnutrennikh del: Avtoref. dis. ... d-ra. yurid nauk. - Chelyabinsk, 2011. - S. 3.

4. Salishcheva N.G. Grazhdanin i administrativnaya yurisdiktsiya. - M., 1979. - S. 72.

5. Dugenets A.S. Kopiya postanovleniya po delu ob administrativnom pravonarushenii kak sredstvo zashchity konstitutsionnykh prav grazhdan // Konstitutsionnoe i munitsipal'noe pravo. - 2002. - № 1. - S. 17.

6. Kurakin A.V. Administrativno-yurisdiktsionnaya deyatel'nost' politsii: problemy teorii // Administrativnoe i munitsipal'noe pravo. - 2014. - 3. - C. 259 - 271. DOI: 10.7256/1999-2807.2014.3.11115.

7. Kurakin A.V. Kompetentsiya politsii v sfere realizatsii zakonodatel'stva ob administrativnykh pravonarusheniyakh // NB: Administrativnoe pravo i praktika administrirovaniya. - 2013. - 4. - C. 28 - 48. DOI: 10.7256/2306-9945.2013.4.8841. URL: http://www.e-notabene.ru/al/article_8841.html

8. Admiralova I.A., Kareeva-Popelkovskaya K.A. Mery administrativnogo presecheniya i mekhanizm ikh realizatsii politsiei $\mathrm{v}$ tselyakh obespecheniya prav i svobod grazhdan // Administrativnoe i munitsipal'noe pravo. - 2014. - 4. - C. 351 - 359. DOI: 10.7256/1999-2807.2014.4.11434.

9. Kurakin A.V. Kompetentsiya politsii v sfere realizatsii zakonodatel'stva ob administrativnykh pravonarusheniyakh // Administrativnoe i munitsipal'noe pravo. - 2013. - 6. - C. 624 - 630. DOI: 10.7256/1999-2807.2013.06.5. 